\title{
Educating Through Mobile Devices: The ABC Game, a Study Case
}

\author{
http://dx.doi.org/10.3991/ijes.v2i3.3817 \\ C. Bortoloti ${ }^{1}$, L. B. Guimarães ${ }^{1}$, L. C. Granato ${ }^{1}$, M. D. Aroldi ${ }^{1}$, V. M. de Souza ${ }^{1}$ \& A. Brawerman ${ }^{1,2}$ \\ ${ }^{1}$ Universidade Positivo, Curitiba, Brazil \\ ${ }^{2}$ Universidade Federal do Paraná, Curitiba, Brazil
}

\begin{abstract}
Electronic games have an important role in contemporary society, affecting it economically, socially and culturally. With a huge market, a proportional number of games, in all flavors, have been offered for all ages, especially for kids, who are patently fond of them. Observing this fact, researchers and teachers realized that games might develop cognitive abilities that formal study could not. Taking advantage of this situation, this paper proposes and presents the development of an educational game for mobile devices aiming to aid small children in the process of literacy, making it playful and engaging, trying at the same time to entertain and to teach, keeping students motivated and, in best cases, leading them to study on their own. The game is composed by several activities involving the alphabet. The activities vary from games that order the alphabet, connect an image to a certain character letter, complete words and unscramble words. There is also a trophy room, in which the student may check the trophies collected during the activities to follow their development.
\end{abstract}

Index Terms-educational methodologies, educational motivation, mobile application games and entertainment.

\section{INTRODUCTION}

Electronic games have an important role in contemporary society, affecting it economically, socially and culturally; and notably the youngsters, who spend a substantial part of their leisure time playing them. One can assume that a child under 10 years old who has access to computers and mobile devices has been raised surrounded by computer games and it can also be inferred that this child is perfectly able to manipulate them with ease.

With a huge market, a proportional number of games, in all flavors, have been offered for all ages, especially for kids who are patently fond of them. Moreover, they are far more appealing than other activities.

Observing this fact, researchers and teachers realized that games might develop cognitive abilities that formal study could not. Taking advantage of this situation, they are using or creating educational games that can, at the same time entertain and teach, keeping students motivated and, in best cases, leading them to study on their own, without requesting.

This paper proposes and presents the development of an educational electronic game for mobile devices aiming to aid small children in the process of literacy, making it playful and engaging. The ABC Game, as it is called, consists of a collection of different activities related to exercising and familiarizing the alphabet and the Portuguese language. Besides, it also helps to develop cognitive abilities, such as touching the screen and moving pieces around (coordination), listening the sounds of words and visualization of images and words. Furthermore, it also helps improving object identification, spelling (ordering of letters) and memory. To motivate the children, each success is awarded with a virtual trophy related to each activity and level. A trophy room is available so that the student may check the collected trophies.

A preliminary version of this game was presented in [1] and following the suggestions from the participant researchers, some enhancements were developed, mainly a new level was added as well as some design and structural modifications in order to improve the learning experience. Besides the complete version of the ABC Game, a free of charge version was also developed and it is also available on the Google Play Store.

\section{FUNDAMENTALS}

Many research works, e.g. [2-5], point that the actual model of learning employed by schools is not following the speed of the children's reasoning, besides the fact that most of the time it does not motivate them. In fact, this model was made by a generation of educators who were not familiarized with a technological apparatus neither electronic games. This gap seems to be decreasing as more research has been published (studies on the subject have began more than 20 years ago) and some consensus has been reached, despite the fact that some authors as Katie Salen warn the overly polemic and shallow debates [6].

Slowly, schools and teachers have begun to adopt games in classes and good results have been observed, especially among the students with weak performance on the traditional methodology [7]. Other aspect observed, and applied, is that the game does not need to be educational, COTS (Commercial Off-The-Shelf) games as Civilization, Sim City, RollerCoaster Tycoon, may work well if the class is carefully prepared and managed.

Previous research work, e.g. [7-10], point that certain types of games work better in certain situation:

- Jeopardy-style: learning of verbal information;

- Card games: ability to match concepts, manipulate numbers, recognize patterns;

- Arcade-style: speed of response, automaticity, visual processing;

- Adventure games: hypothesis testing, problem solving. 
Prensky mentions in [2], that as a game developer, he used to employ well-known computer games to create new challenges. One example was the popular game Doom, of which he picked the 3D-labirinth-style levels to create his educational/instructional software, making it easy, even natural, for most of the students to learn how to play, and adding some thrill as bonus.

In favor of computer games, Van Eck, in [3], indicates that they can be effective learning environments, as they are immersive, have clear goals, require important decisions, adaptability, and may involve social networks. Extremely boring and dry or extremely complicated subjects can become more palatable for students and teachers. Beyond that, games allow learners to develop a set of skills, knowledge, values and an innovative ways of thinking.

Finally, studies presented in [7, 11-13] also observe that educational games claim players to dominate new literacy practices, something not done only through individual mental act but socially. James Paul Gee mentions, in [14], the need of practicing for some time an activity in order to master it, and that this fact can create some barriers for learning in school as students cannot learn deeply by being told things off-context. Computer games act in this sense, involving learners in a world of action and interaction, making them drill diverse skills, repeatedly, relevant to playing the game. Thus, educational games are expected to teach and entertain at the same time, keeping students motivated and, in best cases, leading them to study on their own, without requesting.

\section{METHODOLOGY}

The development of the ABC Game was especially challenging. Since it is a mobile game, for the Operating System Android, it was necessary to optimize animations and interactions, provide ways to motivate children to play, offer a growing knowledge experience and plan the structural part very carefully.

Before start coding, our group searched for similar games available on the market and on papers and books by experts. The group members gave several contributions to form a game set based on the concept of drag-and-drop, the most natural way to interact in a mobile platform.

While providing challenges and engagement to children, our team also wished to reach the maximum number of smartphones as we could. Thus, the Android OS was chosen and despite the fact it is currently on version 4.4, the $\mathrm{ABC}$ Game was developed having in mind version 2.3.3 and up, since there are still a large number of Android users on that version. Figure 1, from the Android developers' forum [15], shows the percentage of users on each available Android version. Note that version 2.3.3 still holds a high number of users.

\section{A. The ABC Game}

The ABC Game is composed by a set of six different games, each of one aim to help children to better understand the alphabet, recognize words and to improve literacy. All the games, except the Alphabet game, are composed by ten different questions. Some of them need dragand-drop actions, while others just need a button click as an answer. At the end of each game, a grade is printed on the screen and a trophy is awarded and added to the Trophy Room. Figure 2 depicts the initial screen of the ABC
Game, in which the user can choose to setup the music and sound effects volume or start to play. Figure 3 shows the main screen, in which the user can choose which game to play or visit the trophy room.

One pedagogical enhancement made in this second version of the ABC Game relates to the use of different colors to easily differentiate the vowels from the consonants and from special characters like accented vowels (á, ã, etc) and altered consonants (ç). This is the technique adopted to draw the attention of small children to the grammatical differences.

\begin{tabular}{|l|l|l|l|}
\hline Version & Codename & AP & Distribution \\
\hline 1.5 & Cupcake & 3 & $0.1 \%$ \\
\hline 1.6 & Donut & 4 & $0.4 \%$ \\
\hline 2.1 & Eclair & 7 & $3.4 \%$ \\
\hline 2.2 & Froyo & 8 & $12.9 \%$ \\
\hline $2.3-$ & Gingerbread & 9 & $0.3 \%$ \\
\hline 2.3 .2 & & 10 & $55.5 \%$ \\
\hline $2.3 .3-$ & & 12 & $0.4 \%$ \\
\hline 2.3 .7 & & 13 & $1.5 \%$ \\
\hline 3.1 & Honeycomb & 15 & $23.7 \%$ \\
\hline 3.2 & & $1.8 \%$ \\
\hline $4.0 .3-$ & Ice Cream & 15 & \\
\hline 4.0 .4 & Sandwich & Jelly Bean & 16 \\
\hline 4.1 & & & \\
\hline
\end{tabular}

Figure 1. Android OS Versions and distribution. From the Android Developer Forum [14].

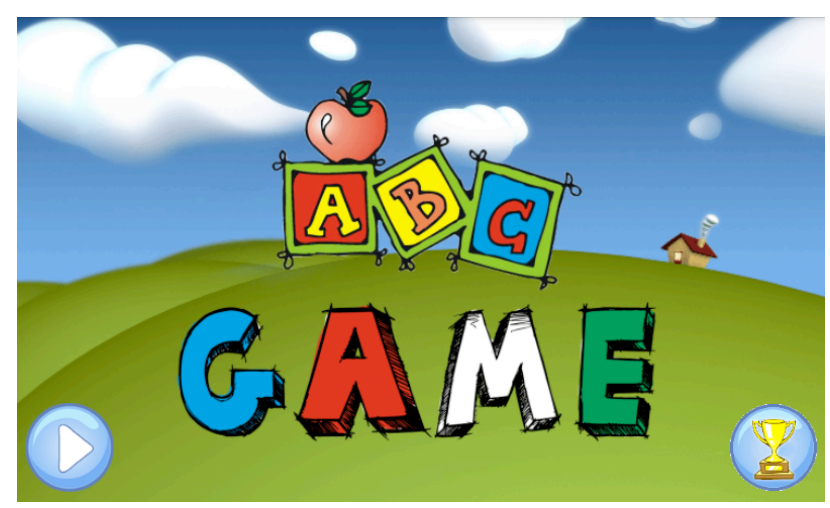

Figure 2. Initial game view.

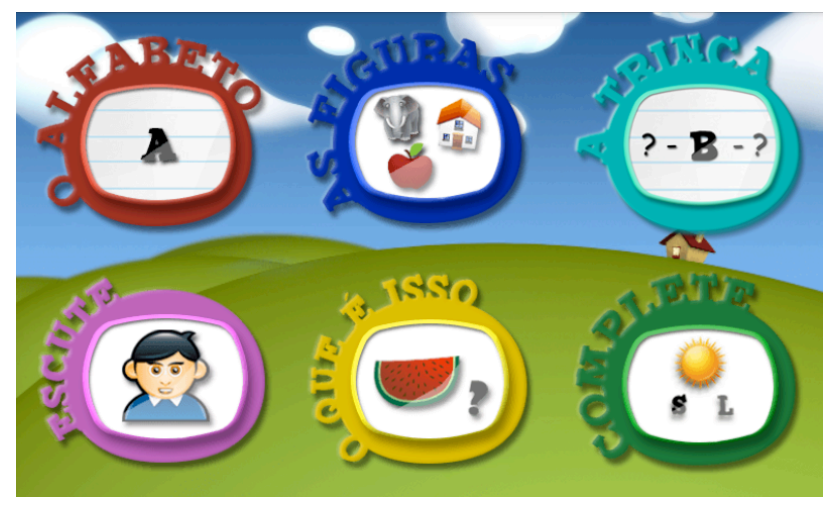

Figure 3. Main game view. 
The first game is named the Alphabet Game. It is a drag-and-drop game in which the player must drag the scrambled letters of the alphabet (Latin based) placed on the bottom of the screen to the chalkboard above. If the player drags and drops the correct letter inside the chalkboard space, it is automatically put in sequence and a sound pronouncing the letter is played. In case of errors, wrong letter or letter placed outside the chalkboard, the piece returns to its original place. Figure 4 shows this game being executed.

In the second game the user has to relate an object depicted in a figure with its name. Each session contains ten different questions, showing one distinct image per question and three words, encapsulated in buttons. When each image appears on the screen, the sound of the pronounced word is heard. The player must choose the right word to go to the next question. In case of errors the image is shaken and the pressed button becomes unavailable. Figure 5 shows a question of this game.

The third game is similar to the previous one. An image is also provided; so that the user knows what word he/she needs to spell, however this time the goal is to complete the word provided. It also presents ten different questions, each one with a single picture and the incomplete spelling of it. A set of letters is positioned at the bottom of the view, some of them being the right ones, which should be dragged and placed on the correct spot. If the player chooses the wrong letter or the right letter is misplaced, a message appears and a sound is played. Figure 6 shows a random question of this game.

The fourth game is the Scrambled Word game. In each question a sound representing a word is played and the correspondent word is presented in a scrambled manner. The user has to unscramble the word to get to the next question. Figure 7 depicts a random question of this game.

In the fifth game, a random letter and 4 images by its side are presented. The player has to choose the image or images in which the word begins with that presented letter. Figure 8 depicts a question of this game.

Finally, the new game is a combination of the Alphabet Game and the Complete Game, called Trinca (or Triplet), where one letter is given and the player should complete the two empty spaces with its neighbor letters. The given letter may be at any position available in the group. The game changes the position and letters showed randomly each phase, helping the children memorize the alphabet in a different way than the Alphabet Game. An example is showed in Figure 9.

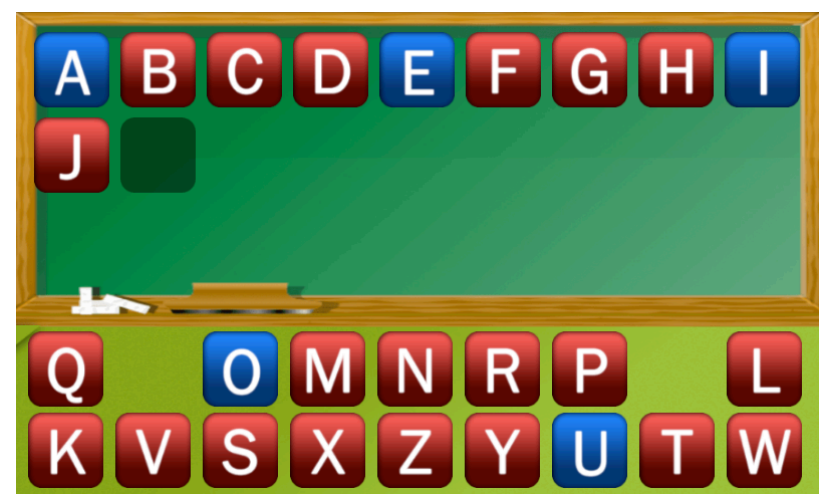

Figure 4. The Alphabet Game.

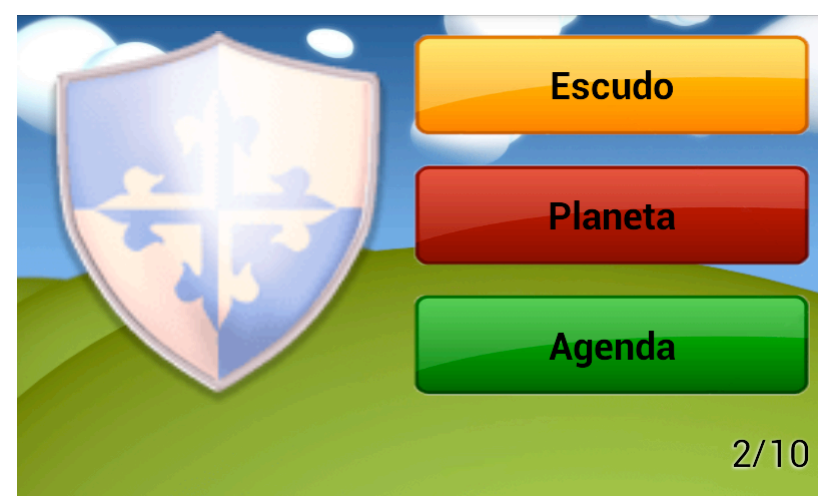

Figure 5. Image-word relation game.

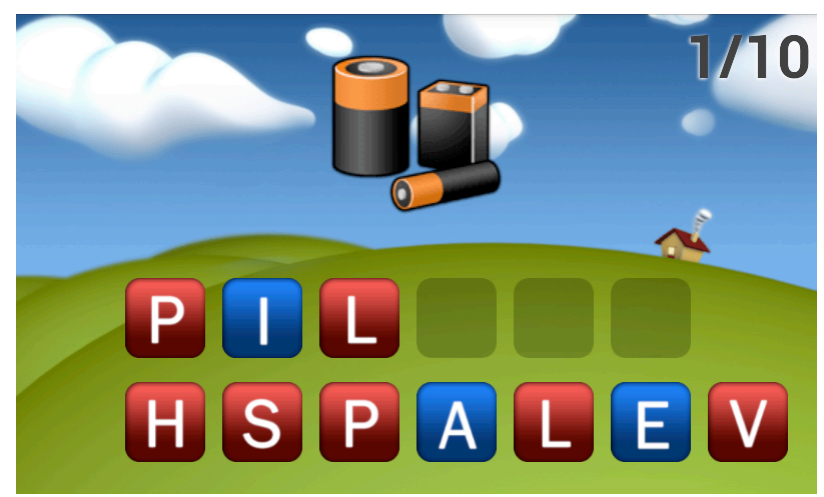

Figure 6. Complete the word.

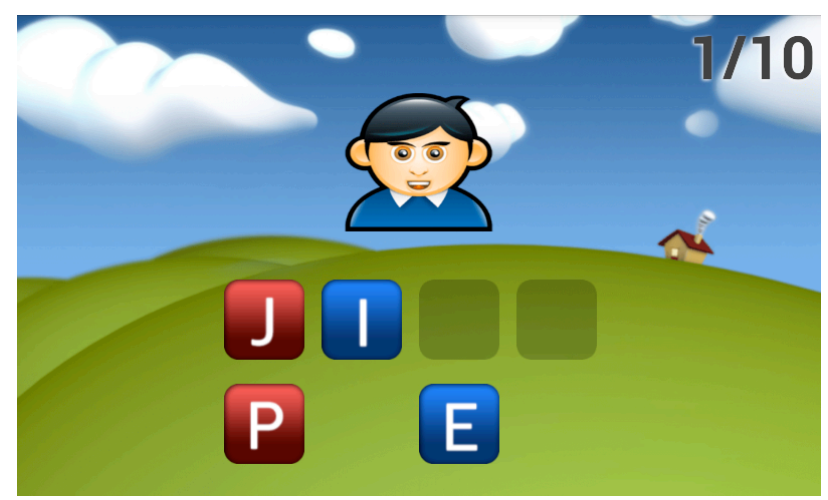

Figure 7. Scrambled Word game.

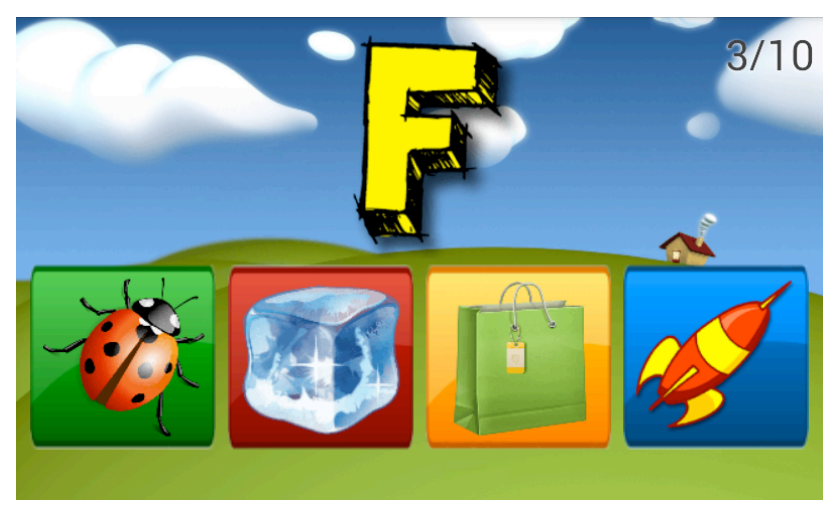

Figure 8. Choose the correct images. 


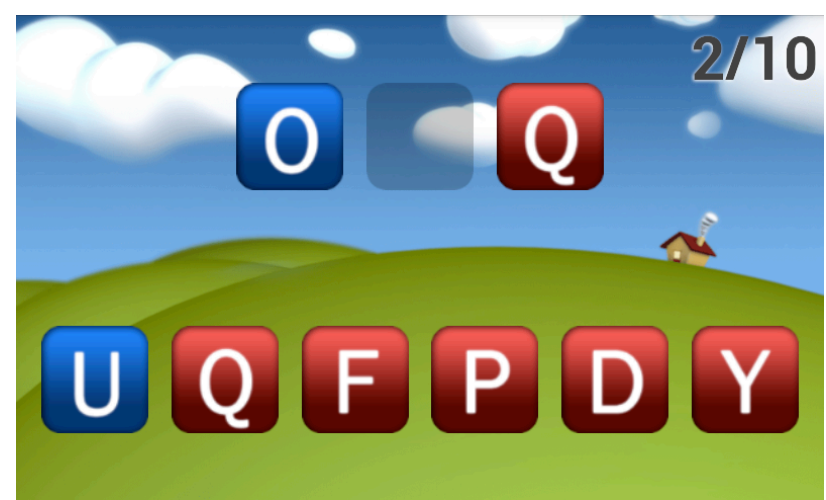

Figure 9. Triplet.

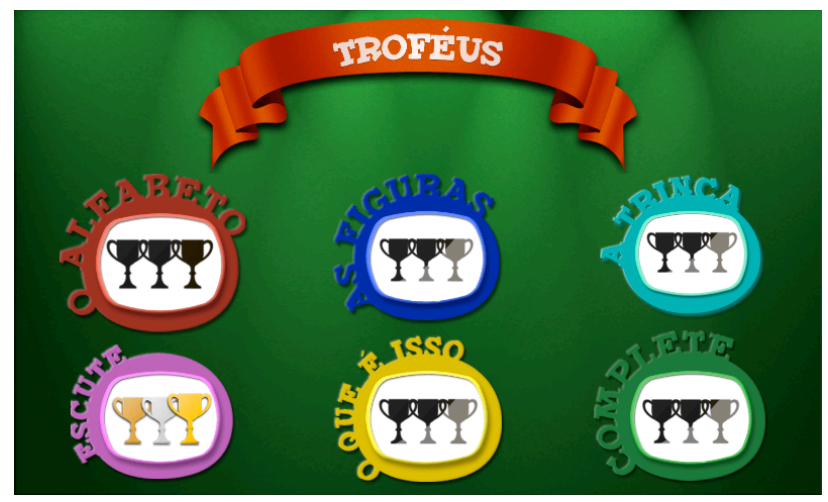

Figure 10. The trophy room.

As mentioned before, to motivate the player a trophy is awarded at the end of each game. The trophy varies from gold, to silver, to bronze, depending on the game final grade. A trophy room is available for the user to check all the trophies he/she has been awarded. Figure 10 shows the trophy room.

\section{B. Development Details}

To develop the game the Eclipse IDE (Integrated Development Environment), the Android SDK (Software Development Kit) and the ADT (Android Developer Tools) Plugin were used.

Some of the games in the ABC Game use the drag-anddrop system to provide a more natural interaction. The Android has in its API 11 the class 'Drag and Drop', however, it is only available in devices that use Android 3.0 or higher. The 'Drag and Drop' class allows the developer to manage the dragging of an element from one view to another (from source to destination). Since we decide to use Android 2.3.3, the solution was to use a single and customized View, in other words, everything that is seen by the child on the screen is contained in one View that is created and modified dynamically. The whole game happens inside the class of this View, which wraps all elements on the screen.

Since the View is draw programmatically, each user interaction is detected through another internal class of the Android API, the MotionEvent class, which is available since the API 1, i.e., Android 1.1. With this class it was possible to detect touching by using the ACTION_DOWN method, dragging with the ACTION_MOVE method, and releasing with the ACTION_UP method.

Another important issue that is involved when developing games or applications for mobile devices is the great variety of sizes and resolution of screens. Therefore, before the game actually begins, the program verifies the dimensions and density of the display. With this information, the size of the changeable elements, i.e., images, letters and the background is adjusted.

\section{The ABC Game Lite}

Besides the full version of the game, we also made available on Google Play a free version called "ABC Game Lite". It has three of the described games above, with the same functionalities: The Alphabet, The Figures and The Triplet. The player also has access to the Trophy Room as in the full version. In the opening screen, there is a link for the player to upgrade to the full ABC Game.

\section{Availability}

The ABC Game is available online on the Google Play Store. The full version can be downloaded at: https://play.google.com/store/apps/details?id=br.com.abcg ame and the free of charge, the ABC Game Lite, can be downloaded at: https://play.google.com/store/apps/details? id=br.com.abcgamelite

\section{CONCLUSIONS}

This paper described the ABC Game, an interesting way of providing a tool for supporting learning through mobile gaming. The game aims to aid small children in the process of literacy and consists of a collection of different activities related to exercising and familiarizing the alphabet. Besides, it also intends to help in the development of cognitive abilities, such as touching the screen (coordination), listening the sounds of words and visualization of images and words. To motivate the children, each success is awarded with a virtual trophy related to each activity and level. A trophy room is available so that the student may check the collected trophies.

We made our best efforts to develop a casual game to be not only instructional, but also fun and engaging. Although it is still a work in progress and it has not yet been tested by children, we have great expectations that it will have a good reception and, mostly, it will serve as a valuable assistance to child literacy. Following the studies of many researchers and observing the popularity of educational games on the App Store and the Google Play Store, we hope to give a small contribution to children's education.

We chose to release only the Android version, as it is the most popular OS at this moment in order to fulfill a larger portion of mobile users/owners. However, a version to another platform is in our plans for future work. At this moment the game is only available in Portuguese, but we also intend to transform the $\mathrm{ABC}$ Game in a bilingual, or even multilingual, collection of educational games, taking advantage of the already available structure (code, pictures).

\section{REFERENCES}

[1] Brawerman A., Bortoloti C., Guimarães L. B., Granato L. C., Aroldi M. D., Souza V. M., "ABC game - educating through mobile devices". Proc. of the Interactive Computer aided Blended Learning Conference Program, Brazil, 2013.

[2] M. Prensky, "Digital game-based learning". New York: McGrawHill, 2001. 
PAPER

Educating Through Mobile Devices: The ABC Game, a Study Case

[3] R. Van Eck. "Digital Game-Based Learning: It's Not Just the Digital Natives Who Are Restless". EDUCAUSE Review March April 2006.

[4] M. Klawe, "Computer games, education and interfaces: The EGEMS project". In Proc. of the Graphics Interface Conference, 1999.

[5] D. Oblinger, "Games and Learning: Digital games have the potential to bring play back to the learning experience". EDUCAUSE, http://www.educause.edu [last access: 09/08/2013], January 2006.

[6] K. Salen."Toward and Ecology of Gaming", available at: http://mitpress.mit.edu/books/full_pdfs/The_Ecology_of_Games.p df p.2, 2008.

[7] M.Virvou, G. Katsionis and K. Manos, "Combining Software Games with Education: Evaluation of its Educational Effectiveness". Educational Technology \& Society, 8 (2), 54-65, 2005.

[8] Facer, R. Joiner, D. Stanton, D. Kirk and R. Hull, "Savannah: experiential learning through mobile gaming". Journal of Computer Assisted Learning. 20 (6), p. 399 - 409, 2004. http://dx.doi.org/10.1111/j.1365-2729.2004.00105.x

[9] M. Papastergiou, "Digital Game-Based Learning in high school Computer Science education: Impact on educational effectiveness and student motivation". Computers \& Education 52 (2009).

[10] D. Oblinger, "The next generation of educational engagement". Journal of Interactive Media in Education, 2004(8), 1-18, 2004.

[11] J. Kirriemuir and A. McFarlane, "Use of Computer and Video Games in the Classroom". Proc. of the Level Up Digital Games Research Conference, Netherlands, 2003.

[12] K. Facer. "Computer Games and Learning: Why do we think it's worth talking about computer games and learning in the same breath?" NESTA Futurelab Review Series, http://www.futurelab.org.uk [last access: 09/08/2013], 2003.

[13] Klawe and E. Phillips, “ A Classroom Study: Electronic Games Engage Children As Researchers”. CSCL '95 Proceedings, October 1995 .
[14] J.P. Gee. What Video Games Have to Teach Us About Learning and Literacy. Houndmills: Palgrave MacMillan, p.68, 2003.

The Android Developer Forum, available at: http://developer. android.com/ [last access: 09/15/2013].

\section{AUTHORS}

A. Brawerman is with the Universidade Positivo and Universidade Federal do Paraná, Curitiba, PR 81280-330, Brazil. Ph.D. in Computer Engineering from the Georgia Institute of Technology (e-mail: brawerman@up.com.br).

C. Bortoloti is with the Núcleo de Computação Embarcada, Universidade Positivo, Curitiba, PR 81280-330 Brazil (e-mail: bortolotic@gmail.com).

L. B. Guimarães is with the Núcleo de Computação Embarcada, Universidade Positivo, Curitiba, PR 81280330 Brazil (e-mail: leoguima94@hotmail.com).

L. C. Granato is with the Núcleo de Computação Embarcada, Universidade Positivo, Curitiba, PR 81280-330 Brazil (e-mail: lucacgranato@gmail.com).

M. D. Aroldi is with the Núcleo de Computação Embarcada, Universidade Positivo, Curitiba, PR 81280-330 Brazil (e-mail: mauricioaroldi@yahoo.com.br).

V. M. de Souza is with the Núcleo de Computação Embarcada, Universidade Positivo, Curitiba, PR 81280330 Brazil (e-mail: vinimendes3@hotmail.com).

This article is an extended and modified version of a paper presented at the ICBL2013 International Conference on Interactive Computer aided Blended Learning, held 6 - 8 November 2013, in Florianópolis, Brasil. Submitted 29 April 2014. Published as resubmitted by the authors 07 August 2014. 